\title{
Maternal Dietary Quality and Socio-demographic Status and their Association with Food Insecurity in the St. George Region of Trinidad and Tobago \\ J John
}

\begin{abstract}
Objective: This exploratory study sought to understand the relationship between food insecurity, socio-demographic status (SDS) and diet quality in a sample of pregnant mothers in Trinidad.

Design and Methods: This qualitative, descriptive study took place in 5 health centres of the North Central Regional Health Authority in Trinidad and Tobago. The target population was healthy expectant mothers of any age and gravida with singleton pregnancies between 12 and 20 weeks' gestation. A convenience sample from each of the health centres was taken. Two hypotheses explored the relationship among the 3 main variables of SDS, dietary quality and food security status (ELCSA).

Results: Seventy-one percent of the mothers had unhealthy pre-pregnancy body mass index. The majority of mothers had a moderate diet quality and as well as SDS. $44 \%$ of households were food secure and $7 \%$ experienced extreme food insecurity. Households with children were less food secure and experienced more severe grades (moderate and extreme) of food insecurity as compared to households without children. Food insecurity was negatively correlated with SDS and consumption of low dietary quality foods positively correlated with SDS. Food insecurity was not statistically significant with diet quality. Multigravidity was not statistically significant with higher diet quality.
\end{abstract}

Conclusions: Contrary to previous studies using the ELCSA, a better social standing was not linked to being food insecure or a high diet quality; as SDS increased diet quality actually decreased. Multigravidity status also did not affect diet quality. Thus other factors may be influencing dietary choices for pregnant women.

Keywords: Diet quality, food insecurity, socio-demographic status, pregnancy

From: Universidad Veracruzana, Xalapa, Veracruz, México

Correspondence: Ms J John, 274 Chestnut Blvd, Bregon Park, D’Abadie Trinidad

E-mail address: temeche@gmail.com. 


\section{INTRODUCTION}

Food security status in pregnant women is a virtually unexplored area in Trinidad and Tobago (TT). Women, especially mothers, are gatekeepers of the family diet, and have long been entrusted with the principal responsibility of selecting, preparing, and serving nutritious foods to support families and households and a better understanding of the relationship of women's diets to patterns of food security in the home and family is needed (1).

Access to nutritious food and food choice is influenced by the social, economic and environmental conditions in which individuals live, with many social determinants of health influencing individual behaviours in relation to food insecurity, such as purchasing, budgeting and food preparation (2). An understanding of the relationship between household food insecurity and dietary adequacy is imperative in appraising the consequences of food insecurity for nutritional health and well-being in women and children (3), as existing evidence of associations between food insecurity and negative pregnancy outcomes is sufficient to merit that women need special consideration in discussions of food insecurity and its effect on health, nutrition, and behaviour (4).

In many studies outside of TT, food insecurity has been implicated in the development of health complications in the pregnant population $(5,6)$, while others show that certain indicators may increase the chance of being food insecure $(7,8)$, while others still highlight the effects/ potential complications of poor nutrition during pregnancy and beyond $(3,9,10,11,12)$. Taking into consideration the evidence from similar studies conducted within the Latin American and the Caribbean and the wider world, and the fact that a study of this nature - food security in the pregnant population - has not been in undertaken prior to this time in TT, this project aims to fill the knowledge gap - not only on their food security status but also their socio-demographic 
profile and critically, their food consumption habits. In addition, the use of the ELCSA (abbreviation in Spanish: the Latin American and Caribbean Food Security Scale) as the instrument of choice to measure food security status is significant as it allows for validation in an English-speaking setting. Furthermore, although there exists research on food security in TT (13, $14,15,16)$, the use of different instruments do not allow for congruency and therefore ease of comparisons within similar populations of the LAC. Lastly, the Regional Food and Nutritional Security Policy of the Caribbean Community (the CARICOM) (17), of which TT is a member, highlights the need for baseline surveys from the region that shed light on the food and nutritional status of in region with a purview on distinct populations -inclusive of gender and age. This study will thus prove itself timely in providing up-to-date data on the pregnant population in TT, add to the growing body of research that occupies the ELCSA as the instrument to measure food security status and, ultimately as a reference for other investigations that may follow.

Food security therefore is a valuable concept if used with a clear understanding of what it means, its limitations, and how it interacts with behaviour and non-food factors (18). The experience of food insecurity measured alongside anthropometric, dietary and sociodemographic data, can provide insight on vulnerabilities and can help in the planning of relevant interventions to target food insecurity populations - namely pregnant women - in a timely manner (19). 


\section{METHODS}

This qualitative, descriptive study took place in 5 health centres of the St George East Region of the North Central Regional Health Authority in Trinidad and Tobago. A convenience sample from each of the health centres was taken. The exclusion for this project were as follows: a. expectant mother does not attend any of the antenatal health clinics of the NCRHA, b. multifoetal pregnancy c. unwillingness to participate in investigation/ no consent given; and inclusion criteria: healthy mothers, with singleton pregnancies of any age and gravida including primigravida, bonafide attendees of any of the health centres within the NCRHA, with a gestational age clearly determined by patient records of 12 to 20 weeks' gestation, and having been informed of the objectives and conditions of the study, and having given written consent to participate (for underage individuals written consent to be obtained from guardian).

Mandatory training was provided to the nursing students who carried out the data collection in the months of November 2014 to January 2015, using guidelines provided in the ELCSA manual (20). The main objective was to evaluate the relationship between dietary quality, socio-demographic status and food security in a sample of pregnant mothers of the St George East Region of TT. This study had two main hypotheses (i): Socio-demographic status (SDS) and overall diet quality are positively and negatively associated respectively with food insecurity in pregnant women of the St George East Region of TT; (ii): Multigravidity is positively associated with a high overall diet quality (high consumption protein rich foods, fruits and vegetables; low consumption of nutrient-poor foods) in pregnant women of the St. George East Region of TT.

The instrument utilised to assess food security status in this present study was the Latin American and Caribbean Food Security Scale (Escala Latinoamericana y del Caribe de 
Seguridad Alimentaria, ELCSA, its acronym in Spanish). The ELCSA is a low cost, rapid application instrument that has demonstrated a high level of validity and reliability and is touted as the answer to the need of an instrument that permits the comparison of food security measurements experienced at the household level among the countries of the Latin American and Caribbean region (20). It contains 15 questions, eight of which pertains to the adults and seven to children (those under 18 years of age) living in the household. All questions refer to the three months preceding the survey, that is, approximately the first three months of gestation. Although designed for administration in the home, the ELCSA has been previously used successfully on a similar population also employing the method of instrument administration in the health centre setting (21).

It has been employed within the non-Latin Caribbean (Haiti) (22), in addition to outside the LAC (Albania) (23), however to the author's knowledge, not within the English-speaking Caribbean region.

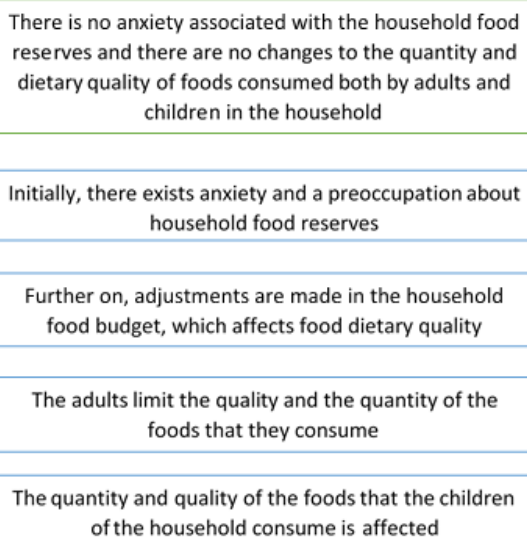

Fig 1: Conceptual framework of household food insecurity as determined by the ELCSA Adapted from the ELCSA Manual, pg. 13 (FAO, 2012) 
The aim of the present study as pertains to the ELCSA was only to linguistically adapt the instrument for the target population, a method that has been previously utilised in the previous research using the ELCSA (24), and to establish its internal validity. Internal validity of the instrument was done using Alpha's Cronbach, and, with respect to qualitative methodologies, face validation (linguistic suitability and appropriate comprehension) of the questions that comprise the food security scale.

The qualitative methods employed to establish face validity was the method of reverse translation proposed by Borsa et al (25). A focus group was utilised, as per guidelines of the ELCSA manual, with the completed English translation to pre-test a number of pregnant women not participating in the study.

Table 1 Classification of Food (in) security according to household category

Type of Household

\section{Classification of Food (In)Security}

$\begin{array}{rrrr}\text { Secure } & \begin{array}{l}\text { Mild food } \\ \text { insecurity }\end{array} & \begin{array}{l}\text { Moderate } \\ \text { food } \\ \text { insecurity }\end{array} & \begin{array}{r}\text { Extreme } \\ \text { food } \\ \text { insecurity }\end{array} \\ 0 & \begin{array}{l}4 \text { to } 6 \\ 0\end{array} & 6 \text { to } 10 & 11 \text { to } 8 \\ & 1 \text { to } 5 & & \end{array}$

To supplement the ELCSA an additional questionnaire was utilised to provide contextual information about the participants, namely their socio-demographic information and food consumption habits; it also included information on smoking habits, pregnancy history and food practices within the household. To establish content validity, the questionnaire was reviewed and edited by professionals 
in the fields of community nutrition and dietetics, food security, public health and psychology. Face validity for this 29 item questionnaire was established using the same method as described earlier with the ELCSA - through the use of a focus group and the pilot phase of the study (26). Dietary quality was based on dietary diversity - that is, the frequency of consumption of the food grouping. It was classified based on three indices a. higher dietary quality foods - frequency of consumption of meats including poultry, vegetables, fruits, milk and milk products, legumes and nuts b. lower dietary quality foods - frequency of consumption of nutrient-poor foods: sweets, snacks, artificial juices and soft drinks) and c. overall diet quality. The overall index was characterised by high intakes of protein-rich foods (plant and/or animal based), fruit and vegetables but by low intakes of snacks, confectionery, chips and artificial juices and soft drinks.

Table 2: Coding of the variables used in statistical analyses

\begin{tabular}{|c|c|c|c|}
\hline \multirow[t]{2}{*}{ Measurement of } & \multicolumn{3}{|c|}{ Classification } \\
\hline & Poor/ Low & Moderate & Desirable/ High \\
\hline Socio-demographic status & 0 to 4 & 5 to 10 & 11 to 15 \\
\hline $\begin{array}{l}\text { Dietary quality (high protein foods, fruit } \\
\text { and vegetables) }\end{array}$ & 0 to 1 & 2 to 3 & 4 \\
\hline Dietary quality (nutrient - poor foods) & 4 & 3 to 2 & 0 to 1 \\
\hline $\begin{array}{l}\text { Dietary quality (nutrient-poor foods) } \\
\text { reverse-coded }\end{array}$ & 0 to 1 & 2 to 3 & 4 \\
\hline Overall diet quality & 0 to 2 & 3 to 5 & 6 to 8 \\
\hline Overall diet quality binary format & 1 & 1 & 2 \\
\hline
\end{tabular}


A healthy pre-pregnancy BMI was classified between 18.5 and 24.9. Any other value was classified as unhealthy. The protocol for this cross-sectional study was approved by the Ethics Committee of the Ministry of Health in Trinidad and Tobago.

Data was analysed using IBM SPSS Statistics version 20. Descriptive statistics were used to depict food security, socio-demographic status, diet quality and other household and individual characteristics of the sample population. Cronbach's alpha was used to ascertain internal validity of the ELCSA. Spearman's Rank-order Correlation for the ordinal variables of food security, SDS and diet quality and Fisher's Exact test with Phi coefficient and an Odds Ratio (95\% confidence interval) for the binary variables of gravidity and overall diet quality. Significance measured at $\mathrm{p} \leq .05$.

\section{RESULTS}

The average age of the pregnant mothers in the sample $(n=43)$ was 26.4 years of age (minimum 17, maximum 36), with $46.5 \%$ of the sample being primigravidas. With respect to pre-pregnancy BMI ( $n=26), 71 \%$ of the pregnant mothers had an unhealthy status, that is underweight, overweight or obese, and $29 \%$ of the mothers having an healthy pre-pregnancy status - within the healthy BMI range of $18.5-24.9$. The Cronbach's alpha for the ELCSA was .846 for households without children and .926 for households with children. The figure below shows distribution of food security status. 


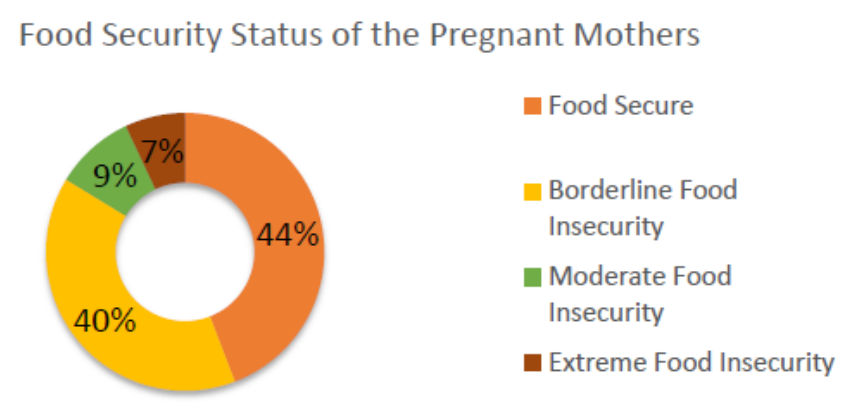

Fig 2: Food Security Status of the Pregnant Women

Dividing the households between those with children and those without, we see that households with children are less food secure:
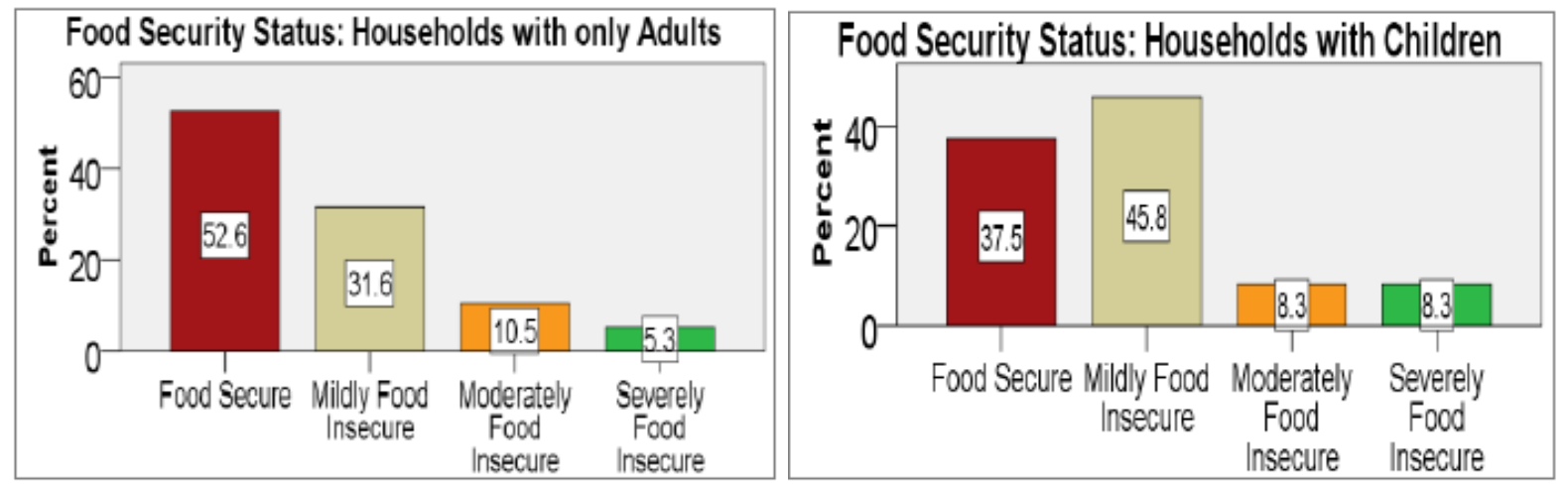

Fig 3: Food security status according to type of household

Only $19 \%$ of the pregnant mothers have a high consumption of protein-rich foods, fruit and vegetables everyday (high diet quality index). The consumption of nutrient poor foods (lower dietary index) showed that $53 \%$ of the pregnant mothers did not partake of these lower quality foods every day, however only $21 \%$ of the pregnant mothers had an overall high quality diet; the vast majority of the mothers had a moderate SDS (see figure below): 


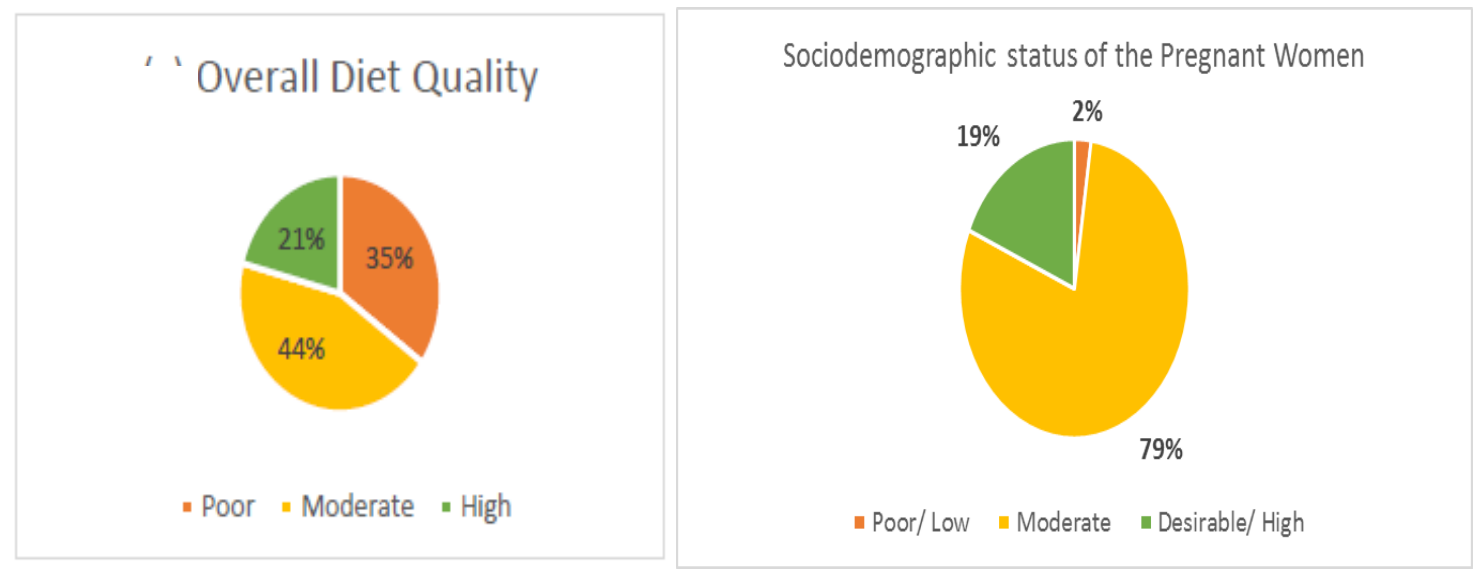

Fig 4: Overall Diet Quality \& Socio-demographic Status of the Pregnant Women

Table 1 shows results for hypothesis I, in addition to select variable combinations using a onetailed Spearman's rank-order correlation. The relationship between food insecurity and SDS was a weak, negative one, which was nonetheless statistically significant, but the correlation between food insecurity and overall diet quality was positive but very weak and not statistically significant.

'Multigravidas tended to take charge of meal preparation and the shopping more than primigravidas. However, primigravidas had a larger proportion lower overall dietary quality as well as a lower consumption of high dietary quality foods, with a higher consumption of low dietary quality foods.
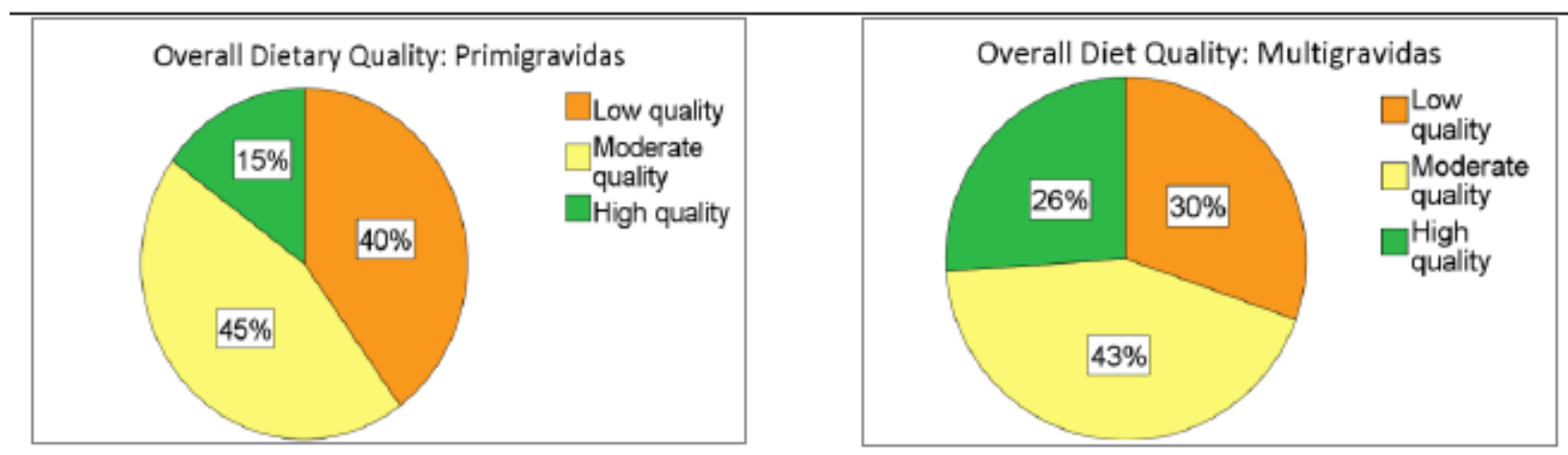
Fig 5: Sample according to parity and overall dietary quality

The null hypothesis was accepted for hypothesis II as the results of the Fisher's Exact test (onetailed) for hypothesis II yielded a p-value of .306. The Phi coefficient was .136 and the Odds ratio of multigravidas having a high diet quality as compared to primigravidas was OR 2.0 95\%CI.049-9.332.

\section{DISCUSSION}

This exploratory study examined the relationship between maternal dietary quality, sociodemographic status and food security status in a sample of pregnant women in Trinidad and Tobago. It is the first of its kind to the author's knowledge that investigates food security status using the ELCSA in the non-Spanish-speaking LAC. The households with children suffered more food insecurity as compared to households without children. In situations of limited resources, Basiotis \& Lino (27) point out that maternal deprivation, where the mother will eat less food so that the children can eat more, is observed. This situation would be especially grave for households with children where the mother is pregnant. This corroborates the observation in the ELCSA Manual that households with children tend to suffer food insecurity more than households without children.

The test of internal consistency was carried out on the ELCSA and, as compared to the other studies in the LAC, the results of the Cronbach's alpha shows good internal validity $(.846$ 
for households without children and .926 for households with children), with both values higher than 0.75 which is considered to be the threshold or minimum acceptable value Another significant observation in the results of the present study is the pre-pregnancy BMI of the mothers: here, $71 \%$ of the mothers had an unhealthy BMI (that is unhealthy, overweight or obese) and $29 \%$ with a normal/ healthy pre-pregnancy BMI, whereas in a study with Colombian mothers it was the inverse: $72.6 \%$ had a normal/ healthy pre-pregnancy BMI, and only $27.4 \%$ falling into unhealthy categories (21). Both maternal pre-pregnancy overweight and obesity and pre-pregnancy underweight increase the risk of adverse outcomes - both for mother and baby (28) and these results are in the least worrying as the link between in utero insults and disease in offspring (especially non-communicable chronic diseases) are increasingly being recognised (29, 30, 31), and, in light of the fact that in the Caribbean region, TT has the highest percentage of deaths attributable to non-communicable chronic diseases (32).

With respect to the first hypothesis the results show that SDS was statistically significant with food security: as households tended towards severe food insecurity, their SDS decreased. This establishes the predictive validity for the ELCSA instrument in this context, as the Manual highlights studies in which this very same pattern was reproduced (20). The relationship between these two variables however was a weak one, and this is attributed to the lack of conventional quantitative indicators in the formulation of the index. Nonetheless, the outcome is encouraging as it shows that a qualitative measure of SDS which includes proxies typical of socio-economic status can achieve significant results. Thus in settings where direct economic data may not be available, use of such an index can be considered.

Hypothesis I also looked at dietary quality and its association with food insecurity. Similar to other studies $(33,34)$, the basis for this hypothesis was that higher dietary quality 
foods (nutrient-dense foods) would be more expensive when compared to lower dietary quality foods (nutrient-poor foods), which are typically more energy dense, and often very palatable due to high sugar, salt and fat content, and thus may not be consumed very regularly by someone with food insecurity.

Overall diet quality was not statistically significant with food security status in this sample of pregnant mothers, neither was consumption of high dietary quality foods, nor consumption of low dietary quality foods, the prediction associated with hypothesis I (results not shown). This is inconsistent with previous studies on an adult population in Trinidad $(14,15)$ and other international studies concerning food insecurity and diet $(35,13,36,8)$.

Important to consider here is the time frame of this study in the gestational period of the pregnant mothers. Food cravings, food aversions, conditions such as nausea and vomiting and even eating disorders all may play a part in maternal diet quality. Thus the intersection of food security and diet quality with food cravings and aversions may be defining factors beyond the scope of this study that may have influenced this outcome.

The null hypothesis was accepted for hypothesis II: multigravidity was not positively associated with a higher overall diet quality in pregnant women of the St. George East Region of TT. The question remains whether these observed dietary patterns are matters of choice or circumstance (37). Future research especially in the area of education, knowledge, attitudes and practices may help to clarify the relationship between multigravidity and dietary quality in TT. 


\title{
Limitations
}

The small sample size may have biased statistical analyses and skewed final results. Convenience sampling was employed therefore it was not possible to assure the heterogeneity of the participants according to SDS.

\author{
Abbreviations \\ BMI - Body Mass Index \\ CARICOM - Caribbean Community \\ ELCSA - Escala Latinoamericana y Caribeña de Seguridad Alimentaria/ Latin American and \\ Caribbean Food Security Scale \\ FAO - Food and Agricultural Organisation of the United Nations \\ LAC - Latin America(n) and Caribbean \\ NCRHA - North Central Regional Health Authority (of Trinidad and Tobago) \\ SDS - Socio-demographic Status \\ TT - Trinidad and Tobago
}

\section{ACKNOWLEDGEMENTS}

The author wishes to express heartfelt thanks to the Primary Care Nurse Manager Callistra Thomas at the CMOH of the St. George East Region of the NCRHA, Dra. Laura Hernández Salazar, Coordinadora de Posgrado en Neuroetología, Universidad Veracruzana, Xalapa, Veracruz, México, the nursing students of the COSTAATT, Jennifer Wears De Four and Dr. Liesl Windsor. 


\section{REFERENCES}

1. USAID'S Infant and Young Child Nutrition Project. Maternal dietary diversity and the implications for children's diets in the context of food security 2012.

2. Tipper, R. Women and Food Insecurity. Melbourne: Women's Health Victoria 2010 (Women's Health Issues Paper 7).

3. Tarasuk, V., \& Beaton, G. Women's Dietary Intakes in the Context of Household Food Insecurity1,2. ASN 1999.

4. Ivers , L., \& Cullen, K. Food insecurity: special considerations for women. Am J Clin Nutr 2011.

5. Laraia, B., Bentley, M. E., \& Borja, J. Food Security and Feeding Strategies. 2006.

6. Laraia, B., Sieg, A., \& Gundersen, C. Household food insecurity is associated with selfreported pregravid weight status, gestational weight gain and pregnancy complications. J Am Diet Assoc. 2010; 110(5), 692-701.

7. Laraia, B., Siega-Riz, A. M., Gundersen, C., \& Dole, N. Psychosocial Factors and Socioeconomic Indicators Are Associated with Household Food Insecurity among Pregnant Women. ASN 2006; 177-182.

8. Mello, J., Gans, K., Risica, P., Kirtania, U., Strolla, L., \& Fournier, L. How is food insecurity associated with dietary behaviors? An analysis with low income, ethnically diverse participants in a nutrition intervention study. ADA 2010; 110(12), 1906-1911. doi:10.1016/j.jada.2010.09.011.

9. Mendoza, L., Pérez, B., \& Sánchez Bernal, S. Estado nutricional de embarazadas en el último mes de gestación y su asociación con las medidas antropométricas de sus recién nacidos. Pediatr. (Asunción) 2010; Vol. 37(2), 91-96. 
10. Ramakrishnan, U., Grant, F., Goldenberg, T., Zongrone, A., \& Martorella, R. Effect of Women's Nutrition before and during Early Pregnancy on Maternal and Infant Outcomes: A Systematic Review. Paediatr Perinat Epidemiol 2012; 26 (Suppl. 1), 285301. doi:10.1111/j.1365-3016.2012.01281.x.

11. Rodriguez-Bernal, C., Rebagliato, M., \& Ballester, F. Maternal nutrition and fetal growth: the role of iron status and intake during pregnancy. Nutr Diet Suppl 2012; 4, $25-$ 37.

12. Amosu, A., \& Degun, A. Impact of maternal nutrition on birth weight of babies. Biomed Res-India 2014; 25(1): 75-78.

13. Gulliford, M. C., Mahabir, D., \& Rocke, B. Food insecurity, food choices, and body mass index in adults: nutrition transition in Trinidad and Tobago. Int J Epidemiol 2003.

14. Gulliford, M., Mahabir, D., \& Rocke, B. Reliability and validity of a short form household food security scale in a Caribbean Community. BMC Public Health. 2004.

15. Gulliford, Mahabir, D., Nunes, C., \& Rocke, B. Self-administration of a food security scale by adolescents: item functioning, socio-economic position and food intakes. Public Health Nutr 2005; 8(7), 853-860.

16. Gulliford, M. C., Nunes, C., \& Rocke, B. The 18 Household Food Security Survey items provide valid food security classifications for adults and children in the Caribbean. BMC Public Health. 2006.

17. CARICOM. Regional Food and Nutrition Security Policy (final draft). 2010.

18. Pinstrup-Andersen, P. Food security: definition and measurement. Food Sec 2009.

19. Ghattas, H. Food security and nutrition in the context of the nutrition transition. 2014. Rome: FAO. 
20. FAO. Escala Latinoamericana Y Caribeña De Seguridad Alimentaria (Elcsa): Manual De Uso Y Aplicaciones. 2012. Roma.

21. Muñoz-Astudillo, M. N., Martínez, J. W., \& Quintero, A. R. Validación de la Escala Latinoamericana y Caribeña de Seguridad Alimentaria en gestantes adolescentes. Salud Pública Méx 2010; 12(2), 173-183.

22. Perez-Escamilla, R., Dessalines, M., Finnigan, M., Pacho, H., Hromi-Fiedler, A., \& Gupta, N. Household Food Insecurity Is Associated with Childhood Malaria in Rural Haiti. ASN 2009.

23. FAO.. Agriculture and Nutrition Department, FAO. 2010. Retrieved from Nutrition Assessment: http://www.fao.org/ag/agn/nutrition/assessment_en.stm.

24. Sánchez Viveros, S., Alvarez Ramírez, M., Cortés Salazar, C., Espinosa Gómez, R., \& Mateu Armand, M. Validación de la Escala Latinoamericana y del Caribe de Seguridad Alimentaria (ELCSA) en el contexto rural y urbano de Veracruz, México. Rev Méd de la Universidad Veracruzana 2014.

25. Callegaro Borsa, J., Figueiredo Damásio, B., \& Ruschel Bandeira, D. Cross-Cultural Adaptation and Validation of Psychological Instruments: Some Considerations. Paidéia (Ribeirão Preto) 2012; 53, 423-432.

26. Carvajal, A., Centeno, C., Watson, R., Martínez, M., \& Sanz Rubiales, Á.¿Cómo validar un instrumento de medida de la salud? An sist sanit Navar 2011; 34(1), 63.

27. Basiotis, P. P., \& Lino, M. Food Insufficiency and Prevalence of Overweight among Adult Women. Fam econ nutr rev 2003; 15(2), 55.

28. Dean, S. V., Imam, A. M., Lassi, Z. S., \& Bhutta, Z. A. Importance of Intervening in the Preconception Period to Impact Pregnancy Outcomes. Matern Child Nutr: The First 
1,000 Days 2013; 63-73. Goa: Nestlé Nutr Inst Workshop Ser. Nestec Ltd. Vevey/S. Karger AG Basel.

29. Lavie, C. J., Milani, R. V., \& Ventura, H. O. Obesity and Cardiovascular Risk: Risk Factor, Paradox and Impact of Weight Loss. J Am Coll Cardiol 2009; 53(21), 1925-1932.

30. Drake, A. J., \& Reynolds, R. M. Impact of maternal obesity on offsprinf obesity and cardiometabolic disease risk. Reproduction 2010; 140(3), 387-98.

31. Lieshout, R. J., Taylor, V. H., \& Boyle, M. H. Pre-pregnancy and pre-pregnancy obesity and neurodevelopmental outcomes in offspring: a systematic review. Obes Rev 2011;12, e548-e559.

32. Pan American Health Organisation. Trinidad and Tobago PANAM STEPS CNCD Risk Factor Survey- Final Report 2012.

33. Drewnowski, A. The cost of US foods as related to their nutritive value. Am J Clin Nutr $2010 ; 92,1181-8$.

34. Leung, C. W., Epel, E. S., Ritchie, L. D., Crawford, P. B., \& Laraia, B. A. Food Insecurity Is Inversely Associated with Diet Quality of Lower-Income Adults. J Acad Nutr Diet 2014; 114(12), 1943-1953.

35. Tarasuk, V. S. Household Food Insecurity with Hunger Is Associated with Women's Food Intakes, Health and Household Circumstances. ASN 2001.

36. Carmichael, S. L., Yang, W., Herring, A., Abrams, B., \& Shaw, G. M. Maternal Food Insecurity is Associated with Increased Risk of Certain Birth Defects. J Nutr 2007; 137(9), 2087-2092.

37. Barrett, C. B. Measuring Food Insecurity. Am J Sci 2010; 327(5967), pp. 825-828. doi:10.1126/science.1182768. 